Louisiana State University

LSU Digital Commons

8-1-2017

\title{
Preservation or piracy: Diagnosing low-relief, high-elevation surface formation mechanisms
}

\author{
Kelin X. Whipple \\ School of Earth and Space Exploration \\ Roman A. DiBiase \\ Pennsylvania State University \\ William B. Ouimet \\ University of Connecticut \\ Adam M. Forte \\ School of Earth and Space Exploration
}

Follow this and additional works at: https://digitalcommons.Isu.edu/geo_pubs

\section{Recommended Citation}

Whipple, K., DiBiase, R., Ouimet, W., \& Forte, A. (2017). Preservation or piracy: Diagnosing low-relief, highelevation surface formation mechanisms. Geology, 45 (8), e422-e422. https://doi.org/10.1130/G39252Y.1

This Letter to the Editor is brought to you for free and open access by the Department of Geology and Geophysics at LSU Digital Commons. It has been accepted for inclusion in Faculty Publications by an authorized administrator of LSU Digital Commons. For more information, please contact ir@lsu.edu. 


\section{Preservation or piracy: Diagnosing low-relief, high-elevation surface formation mechanisms}

\author{
Kelin X. Whipple ${ }^{1}$, Roman A. DiBiase ${ }^{2}$, William B. Ouimet ${ }^{3}$, \\ and Adam M. Forte ${ }^{1}$ \\ ${ }^{1}$ School of Earth and Space Exploration, Arizona State University, \\ Tempe, Arizona 85281, USA \\ ${ }^{2}$ Department of Geosciences, Pennsylvania State University, University \\ Park, Pennsylvania 16803, USA \\ ${ }^{3}$ Department of Geography and Center for Integrative Geosciences, \\ University of Connecticut, Storrs, Connecticut 06269, USA
}

We welcome this opportunity to clarify a few important points from our paper (Whipple et al., 2017a), and note that there is more agreement than disagreement in this debate (see Comment by Willett [2017]). We take issue not with the area-loss feedback (ALF) model in general, but with its viability as a primary explanation for the formation of the extensive lowrelief surfaces of the southeast Tibetan Plateau (Yang et al., 2015). Our main concern is whether or not elevated low-relief surfaces generated by the ALF mechanism could be misinterpreted as remnants of an incised preexisting landscape (PES model) or vice-versa.

Although we agree on the physics and kinematics of fluvial landscape evolution, we disagree with the argument that there are four competing models at play in this debate (Willett, 2017): the ALF, the "strict" PES model, the "modified" PES model, and the "strawman" model of our figure $1 \mathrm{~b}(2017 \mathrm{a})$. This is misleading for two reasons. First, the simulation presented in our figure $1 \mathrm{~b}$ was offered as an illustration of how major drainage area loss via river capture can lead to formation of large areas of low-relief uplands (see Lavé, 2015) and should not be confused with an independent model. The ALF mechanism is indeed not manifest in that simulation. Second, the "strict" PES model embeds too many simplifying assumptions to accurately describe any natural landscape. As we articulated in our paper, we consider a "modified" PES model that allows for drainage network re-arrangement and expected spatial variations in initial conditions, forcing mechanisms, and landscape response.

Diagnostic criteria in landscape evolution are admittedly not easily determined and Willett has raised some important challenges to the examples highlighted in our paper. We agree that local complexities can introduce ambiguities, requiring examination of multiple criteria in a regional context. Yet, we are pleased to see that Willett is in general agreement with the landscape characteristics that we proposed for distinguishing the ALF and PES mechanisms of low-relief surface formation: co-planarity of low-relief surfaces, coincidence of drainage divides, river profile forms, and the presence or absence of high-relief rims. Each has limitations: (1) co-planarity will be most definitive where low-relief surfaces occur over a wide geographic area; (2) coincidence of divides and low-relief surface boundaries is expected, but not required, in the ALF model (Willett, 2017), and may form in the PES model as a consequence of local variability in landscape response; (3) recent drainage area change is just one of many factors that can cause spatial variability in river profile forms and knickpoint elevations - indeed river profiles can quickly erase the influence of drainage area change (Whipple et al., $2017 \mathrm{~b}$ ) - necessitating a regional assessment of river profile forms; and (5) high-relief rims are only characteristic of surfaces formed in response to major drainage capture events and will only be preserved in earlier stages of surface formation (Lavé, 2015; Whipple et al., 2017a). Where the ALF mechanism is active, encroachment of low-relief surfaces from multiple directions will remove any initial high-relief rims (Willett, 2017).

Because of these complications, the above criteria only have discriminating power when taken together and evaluated in regional context. For example, the ALF mechanism should generate local low-relief surfaces at aa range of elevations that would not easily be confused with remnants of a previously continuous surface. Additionally, areas where relief has been reduced as a consequence of drainage area loss will exhibit generally coincident divides, variable relief and erosion rate, and variable preservation of high-relief rims. River profiles will not exhibit any regional consistency in form owing to spatial variations in the timing, rate, and amount of drainage area change. The opposite is generally expected where the PES model is dominant. In this case, low-relief surface patches will have consistent elevations, relief, and erosion rate (allowing for initial variability of the preexisting landscape), generally lack coincident divides, and support no highrelief rims. River profiles will show regional consistency, allowing for local variability in properties, initial conditions, or landscape response. Expected drainage network re-arrangement may recognizably overprint regional patterns.

Despite much common ground, we stand firm in our interpretation of the landscapes of the southeastern margin of the Tibetan Plateau (Whipple et al., 2017a). We reject a dominant role for the ALF mechanism in this setting not simply because of the lack of high-relief rims, but because most surface patches at once fail to meet the criteria diagnostic of the ALF model and meet those diagnostic of the PES model, particularly when considered in the context of the surrounding landscape. Most importantly, the more northerly surface patches highlighted in our paper are generally co-planar and merge to the northwest with the undissected Tibetan Plateau. Further, our analysis of river profiles is distinct from that of Yang et al. (2015) not because of a difference in scale or detail but because we evaluate river profiles in the regional context required to discriminate the dominant mechanism. Our analysis reveals regionally consistent river profile forms that in combination with extensive, generally co-planar lowrelief surfaces and a general lack of coincident divides and high-relief rims strongly favor the PES model. The steady-state relief implied by river profiles is a red herring, as evolution to steady state is neither required for the PES model, nor expected in this setting.

As noted by Willett, a few of the surface patches southeast of "CJ10" (Yang et al., 2015, their figure 1) do have largely coincident divides, leaving room for debate. Yet, low-relief surface patches in this area are all nearly co-planar, define an upper envelope to the topography, and thus strongly imply on-going dissection of a preexisting low-relief surface. Although we disagree with their interpretation of the southeastern margin of the Tibetan Plateau, other landscapes likely do preserve low-relief surfaces dominantly formed by the ALF mechanism. Careful attention should always be given to the role of mobile divides in landscape evolution.

\section{REFERENCES CITED}

Lavé, J., 2015, Earth Science: Landscape inversion by stream piracy: Nature, v. 520, , p. 442-444, doi:10.1038/520442a.

Whipple, K.X., DiBiase, R.A., Ouimet, W.B., and Forte, A.M., 2017a, Preservation or piracy: Diagnosing low-relief, high-elevation surface formation mechanisms: Geology, v. 45, p. 91-94, doi:10.1130/G38490.1.

Whipple, K.X., Forte, A.M., DiBiase, R.A., Gasparini, N.M., and Ouimet, W.B., 2017b, Timescales of landscape response to divide migration and drainage capture: Implications for the role of divide mobility in landscape evolution: Journal of Geophysical Research: Earth Surface, v. 122, p. 248273, doi: $10.1002 / 2016 J F 003973$.

Willett, S., 2017, Preservation or piracy: Diagnosing low-relief, high-elevation surface formation mechanisms: Comment: Geology: v.45, doi:10.1130 /G38929C.1

Yang, R., Willett, S.D., and Goren, L., 2015, In situ low-relief landscape formation as a result of river network disruption: Nature, v. 520, p. 526-529, doi:10.1038/nature14354. 